\title{
Huge Hemangioma in the Chest Mimicking a Breast Tumor: Report of a Case
}

\author{
Masao Tadakoshi, MD, Hiroyuki Ishibashi, MD, PhD, Yuki Orimoto, MD, Ikuo Sugimoto, MD, PhD, \\ Hirohide Iwata, MD, PhD, Tetsuya Yamada, MD, PhD, Noriyuki Hida, MD, and Takashi Ohta, MD, PhD
}

\begin{abstract}
A 35 year-old man first noticed an elastic mass like breast tumor in his left chest 17 years ago. It enlarged to the size of a child's head. Computed tomography showed a well-circumscribed mass in the left chest. Lumpectomy was performed. The mass was located under the thin major pectoralis muscle, covered with a white fibrous capsule. The specimen weighed $1360 \mathrm{~g}$ and measured $18 \times 14 \times 8 \mathrm{~cm}$. Histological examination revealed a cavernous hemangioma. To the best of our knowledge, this is the first reported case of a chest hemangioma arising from connective tissue and located under the major pectoralis muscle.
\end{abstract}

Keywords: cavernous hemangioma, huge hemangioma, chest

\section{INTRODUCTION}

$\mathrm{C}$ Yavernous hemangiomas of the chest are rarely described. They do not usually grow except to keep pace with normal body growth. We report a case of a huge, cavernous hemangioma in the chest, arising from connective tissue beneath the major pectoralis muscle, that had enlarged over seventeen years.

CASE

A 35 year-old man suffered from a huge left chest mass like breast tumor. He noticed it seventeen years ago, and it had enlarged gradually to the size of a child's head. He did not complain of pain or dysfunction of the upper limb. He consulted a university hospital and underwent a sample biopsy, which revealed a cavernous hemangioma. He was referred to our hospital for surgical resection. He had no history of trauma or injury.

On physical examination, the mass had a smooth

Department of Vascular Surgery, Aichi Medical University, Nagakute, Aichi, Japan

Received: April 14, 2011; Accepted: March 27, 2012

Corresponding author: Masao Tadakoshi, MD. Department of Vascular Surgery, Aichi Medical University, Nagakute, Aichi 4801195, Japan

Tel: +81-561-62-3311, Fax: +81-561-63-6841

E-mail: masatada@aichi-med-u.ac.jp surface and was elastic and soft, the size of a child's head located in the left chest. Striae cutis were seen in the overlying skin (Fig. 1). The tumor was movable and was not fixed to the chest. Computed tomography (CT) showed a huge tumor in the left chest measuring of $17 \mathrm{~cm}$ in diameter. The surface was smooth and well-circumscribed. The major pectoralis muscle was expanded over the tumor. Microcalcification, suggesting a phlebolith, was seen in the mass. Feeding arteries were not identified. The mass was little enhanced at the early phase and weakly enhanced at the late phase (Fig. 2). Gadolinium-enhancement magnetic resonance imaging (MRI) showed heterogeneous and weak enhancement.

Resection surgery was performed under general anesthesia. An oblique, spindle-shape skin incision was applied on the left chest. The mass was located under the expanded thin major pectoralis muscle and was covered with a white fibrous capsule (Fig. 3). The surrounding connective tissue was crude, and the tumor was easily resected by sharp and blunt dissection. The feeding arteries were small branches of the lateral thoracic artery. The excised specimen weighed $1360 \mathrm{~g}$ and measured $18 \times$ $14 \times 8 \mathrm{~cm}$. The cut surface of the specimen was darkbrown and solid. Histological examination revealed a cavernous hemangioma (Fig. 4). The postoperative course was uneventful, and there was no disturbance of the left upper limb. He was discharged on post-operative day 7 in good condition. 


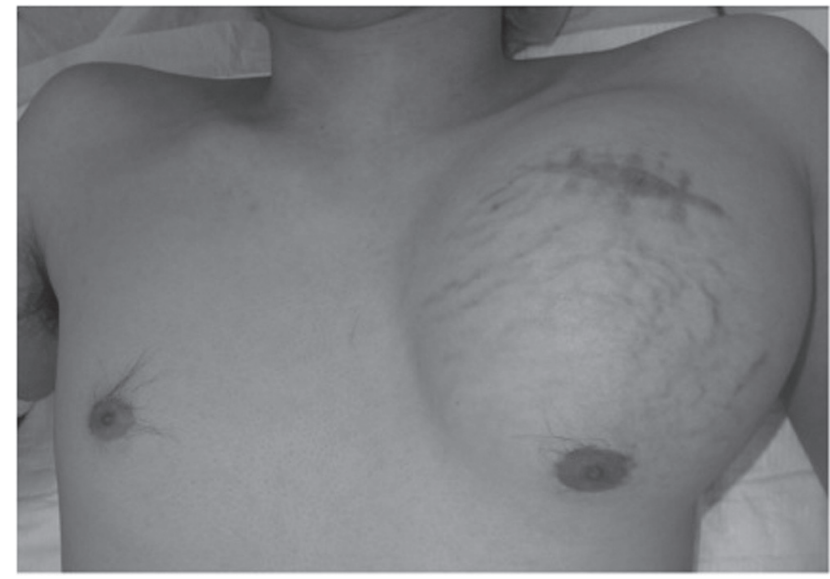

Fig. 1 Macroscopic view of the mass: The left chest tumor was enlarged to the size of a child head. Striae cutis were seen in the overlying skin. The scar was due to the previous incisional biopsy.

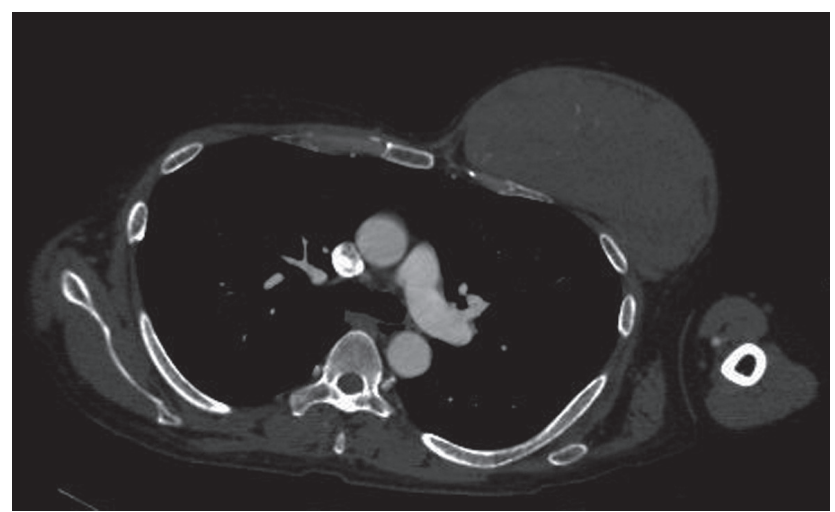

Fig. 2 Computed tomographic scan of the chest: A huge mass of the anterior chest was slightly enhanced.

\section{Discussion}

Cavernous hemangiomas of the chest are uncommon, benign tumors, and especially, noncutaneous cavernous hemangiomas are rare. ${ }^{1,2}$ Differential diagnosis of the chest wall includes lipoma, schwannoma, neurofibroma, which are relatively common.

Cavernous hemangiomas typically appear at birth or before the age of 30 years, but do not usually grow except to keep pace with normal body growth. ${ }^{3)}$ In this case, the tumor had grown to the size of a child's head over a seventeen-year period.

Cavernous hemangiomas generally show distinct enhancement in contrast CT and MRI1, however, some hemangiomas do not. ${ }^{4}$ According to a search of PubMed, three cases of chest cavernous hemangiomas as large as

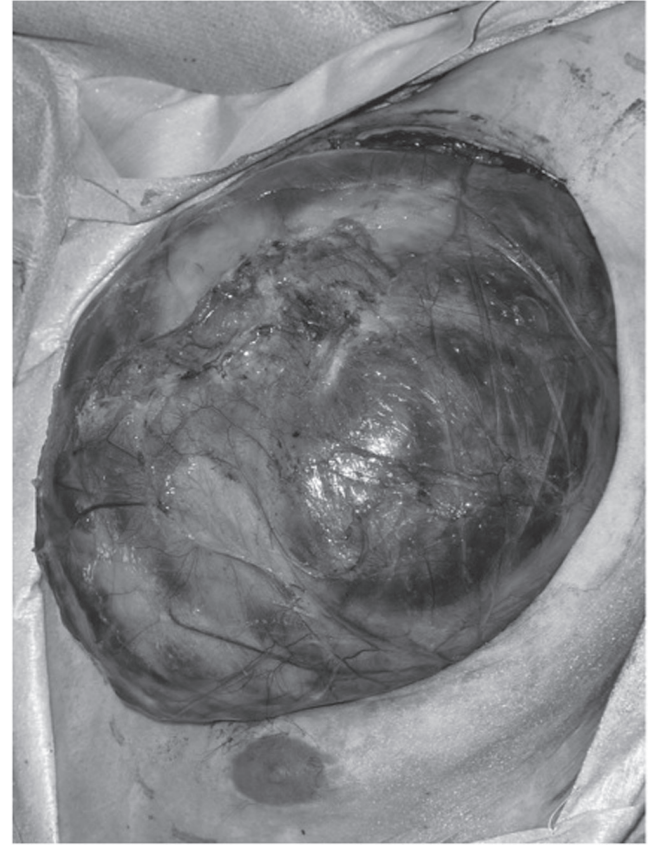

Fig. 3 Intraoperative view of the lesion: The mass was well-circumscribed and the capsule was translucent.

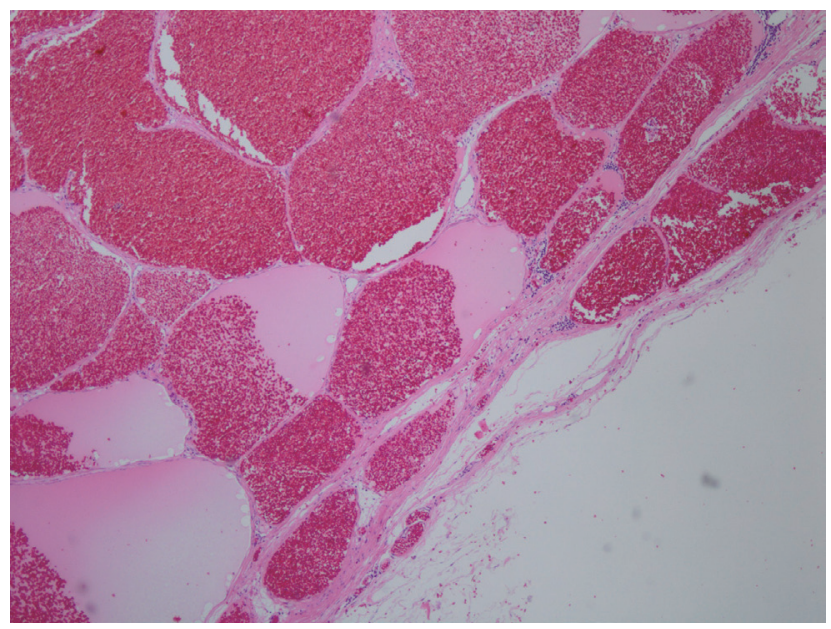

Fig. 4 Hematoxylin and eosin-stained section: The tumor consisted of a large number of dilated vessels filled with red blood cells. (original magnification $\times 40$ )

$10 \mathrm{~cm}$ or larger in diameter have been reported. In one case, contrast CT showed weak and heterogeneous enhancement. ${ }^{3)}$ In another case, contrast MRI showed slow and continuous enhancement in the peripheral portion. ${ }^{5)}$ In another case, an angiogram could identify feeder vessels. ${ }^{6}$ In our case, contrast CT and MRI showed weak and heterogeneous enhancement, but feeding vessels could not be identified (Table 1). 
Table 1 Reported cases of huge cavernous hemangiomas of the chest

\begin{tabular}{|c|c|c|c|c|c|c|}
\hline Author & Year & Age, sex & Location & $\begin{array}{c}\text { Involvement of } \\
\text { adjacent structure }\end{array}$ & Size $(\mathrm{cm})$ & Weight (g) \\
\hline Gopal & 2005 & 26 y.o., female & Breast & Skin & $12 \times 10$ & \\
\hline Kim & 2006 & 18 y.o., female & Breast & Non & $13.5 \times 12 \times 6$ & 660 \\
\hline Kinoshita & 2005 & 60 y.o., male & Breast & Rib & 14 & 2050 \\
\hline Our case & 2011 & 35 y.o., male & $\begin{array}{c}\text { Chest wall } \\
\text { (under major pectoralis muscle) }\end{array}$ & Non & $18 \times 14 \times 8$ & 1360 \\
\hline
\end{tabular}

y. o.: year-old

Although chest cavernous hemangiomas in the mammary gland ${ }^{5)}$ and subcutaneous tissue ${ }^{7,8)}$ have been reported, there was no reported case of hemangioma arising from connective tissue under the major pectoralis muscle. This case is the first reported case. In the three reported cases of huge chest cavernous hemangiomas, a skin change simulating an inflammatory carcinoma appeared in one case. ${ }^{6}$ ) In the other three cases, including our case, there was no change of the overlying skin. Three cases including ours had no involvement of the ribs or deeper structure, but one case involved ribs and intercostal muscle and radical resection was performed (Table 1). ${ }^{3)}$

Although chest cavernous hemangiomas are benign, complete resection is recommended to exclude the possibility of underlying angiosarcoma. ${ }^{3)}$

\section{Conclusions}

Huge chest cavernous hemangiomas may not show a distinct enhancement in contrast CT or MRI differently from other typical cavernous hemangiomas. Although chest cavernous hemangiomas in the mammary gland and subcutaneous tissue have been reported, our case is the first reported case of cavernous hemangioma arising from connective tissue under the major pectoralis muscle.

\section{Disclosure Statement}

Masao Tadakoshi and coauthors have no conflict of interest.

\section{REFERENCES}

1) Tateishi U, Gladish GW, Kusumoto M, et al. Chest wall tumors: radiologic findings and pathologic correlation: part 1. Benign tumors. Radiographics 2003; 23: 1477-90. [Medline] [CrossRef]

2) Griffo S, Stassano P, De Luca G, et al. Intramuscular hemangioma of the chest wall: an unusual tumor. $\mathrm{J}$ Thorac Cardiovasc Surg 2007; 134: 1368-9. [Medline] [CrossRef]

3) Kinoshita S, Kyoda S, Tsuboi K, et al. Huge cavernous hemangioma arising in a male breast. Breast Cancer 2005; 12: 231-3. [Medline] [CrossRef]

4) Hashimoto H, Oshika Y, Obara K, et al. Intercostal venous hemangioma presenting as a chest wall tumor. Gen Thorac Cardiovasc Surg 2009; 57: 228-30. [Medline] [CrossRef]

5) Kim SM, Kim HH, Shin HJ, et al. Cavernous haemangioma of the breast. Br J Radiol 2006; 79: e177-80. [Medline] [CrossRef]

6) Gopal SV, Nayak P, Dharanipragada K, et al. Breast hemangioma simulating an inflammatory carcinoma. Breast J 2005; 11: 498-9. [Medline] [CrossRef]

7) Carreira C, Romero C, Rodriguez R, et al. A cavernous haemangioma of breast in male: radiologicalpathological correlation. Eur Radiol 2001; 11: 292-4. [Medline] [CrossRef]

8) Franco RL, de Moraes Schenka NG, Schenka AA, et al. Cavernous hemangioma of the male breast. Breast J 2005; 11: 511-2. [Medline] [CrossRef] 